\title{
Analisis Biaya Produksi dan Keuntungan Bagi Peternak Muslim di Kawasan Sentra Produksi (KSP) Payakumbuh Sumatera Barat
}

\section{Deltri Apriyeni}

Magister Manajemen STIE KBP Padang Sumatera Barat, deltri.apri@gmail.com

\section{Wati}

Acounting Education Department, STKIP PGRI Sumatera Barat,. tegowati73@gmail.com

Meri Rahmania

Economics Education Department, STKIP PGRI Sumatera Barat, rahmatullah.4j@gmail.com

\begin{tabular}{|c|c|c|}
\hline \multicolumn{3}{|c|}{$\begin{array}{l}\text { (C) () () } \\
\text { for possible open access publicatio } \\
\text { (CC-BY-SA) license (https://creat }\end{array}$} \\
\hline Diterima: 23 November 2020 & Direvisi : 16 Desember 2020 & Diterbitkan: 31 Desember 2020 \\
\hline
\end{tabular}

\begin{abstract}
This study aims to describe the advantages of the Payakumbuh Production Center Area (popular as KSP) as a suitable production area in terms of production cost efficiency and business profits obtained by Muslim stockbreeder in the Payakumbuh area of West Sumatra. The study was conducted on Payakumbub KSP and as comparative data taken business locations that are outside Payakumbuh KSP. The data used are primary data obtained from laying hens breeders. The total number of breeders in the KSP location was made as research objects i.e. 67 people and as a comparison data using 67 farmers who had business locations outside the KSP. The analyszed data using statistics with different test formulations between the two business locations. The results showed that there was no characteristic difference between breeders who tried at the Payakumbub KSP business location and outside the Payakumbuh KSP. Based on the difference test between the two business locations, there is a significant difference in production costs and business profits obtained between breeders located on the Payakumbuh KSP and outside the Payakumbuh KSP. This study recommends the importance of the Payakumbuh KSP in determining the sustainability of the business run by breeders.
\end{abstract}

Keywords: Production Center Area (KSP), Production costs, Business profits.

\begin{abstract}
Abstrak
Penelitian ini bertujuan untuk memaparkan keunggulan Kawasan Sentra Produksi (KSP) Payakumbuh sebagai kawasan produksi yang sesuai dari segi efisiensi biaya produksi dan keuntungan usaha yang diperoleh para peternak muslim di daerah Payakumbuh Sumatera Barat. Studi dilakukan di KSP Payakumbuh dan sebagai data pembanding diambil lokasi usaha yang berada di luar KSP Payakumbuh. Data yang digunakan merupakan data primer yang diperoleh dari peternak ayam petelur. Jumlah total peternak di lokasi KSP dijadikan sebagai objek penelitian yaitu 67 orang dan sebagai data pembanding menggunakan 67 peternak yang memiliki lokasi usaha di luar KSP. Data dianalisis menggunakan statistik dengan formulasi uji yang berbeda antara dua lokasi usaha. Hasil penelitian menunjukkan bahwa tidak ada perbedaan karakteristik antara peternak yang mencoba di lokasi usaha KSP Payakumbuh dengan di luar KSP Payakumbuh. Berdasarkan uji beda antara kedua lokasi usaha, terdapat perbedaan yang signifikan antara biaya produksi dan keuntungan usaha yang diperoleh antara peternak yang berada di KSP Payakumbuh dan di luar KSP Payakumbuh. Studi ini
\end{abstract}


merekomendasikan pentingnya keberadaan KSP Payakumbuh dalam menentukan kelangsungan usaha yang dijalankan oleh para peternak.

Kata Kunci: Kawasan Sentra Produksi (KSP), Biaya produksi, Keuntungan usaha.

\section{Pendahuluan}

Terbentuknya kawasan sentra produksi ini didasarkan kepada kegiatan ekonomi yang berkembang di suatu wilayah, seperti; bidang pertanian, peternakan, perkebunan, industri kecil, kerajinan tangan, dll. Tujuan pembentukan kawasan ini agar lebih dapat mengoptimalkan kegiatan ekonomi, menekankan efisiensi, kemudahan dalam berproduksi dengan mengembangkan teknologi, pemasaran hasil produksi, memperkuat posisi tawar (bargaining position) produsen, ${ }^{1}$.

Dalam ilmu ekonomi Islam, produksi harus diusahakan agar sumber daya alam ciptaan Allah diolah dengan baik, etika dan norma produksi harus diutamakan, kemaslahatan rakyat lebih penting dari pada kemaslahatan sendiri, alat-alat produksi dipergunakan dengan amanah untuk memakmurkan bumi ${ }^{2}$. Sebagai proses dalam menghasilkan barang dan jasa, berdasarkan ketersediaan faktor-faktor produksi perlu memperhatikan nilai-nilai keadilan dan kebajikan (maslahah). Sedangkan Amshari ${ }^{3}$ menjelaskan bahwa dalam produksi syariah biaya yang digunakan akan lebih efisien jika dilakukan dengan cara bagi hasil. Karena dalam

1 S Sjafrizal, Regional Economic Analysis and Its Application (Jakarta: PT. Rajawali Pers, 2018).

2 S. Wahyuni, 'Teori Konsumsi Dan Produksi Dalam Perspektif Ekonomi Islam', Jurnal Akuntabel, 10.1 (2013); Fita Nurotul Faizah, 'Teori Produksi Dalam Studi Ekonomi Islam Modern: Analisis Komparatif Pemikiran Muhammad Baqir Al-Sadr Dan Muhammad Abdul Mannan' (UIN Walisongo, 2016); Misbahul Ali, 'Prinsip Dasar Produksi Dalam Ekonomi Islam', LISAN AL-HAL: Jurnal Pengembangan Pemikiran Dan Kebudayaan, 7.1 (2013), 19-34.

3 M Amshari, 'Analisis Biaya Dan Efisiensi Produksi Dalam Ekonomi Islam', Jurnal Balanca, 1.1 (2019).

Deltri Apriyeni, Wati, Meri Rahmania ekonomi Islam seperti yang diungkapkan oleh Sholiha, tidak dikenal sistem bunga melainkan sistem bagi hasil (revenue sharing), profit sharing dan profit and loss sharing. Selanjutnya, Manik (2013) ${ }^{4}$ menjelaskan bahwa, pengembangan kawasan bertujuan untuk mengembangkan agribisnis yang berwawasan lingkungan, meningkatkan nilai tambah dan daya saing, mendayagunakan sumber daya, meningkatkan pendapatan masyarakat dan PDRB, serta melakukan re-positioning pemasaran di tingkat nasional dan global. Selanjutnya Hidayat (2016) ${ }^{5}$, menjelaskan bahwa keberadaan sektor usaha dihulu dan dihilir serta terkaitnya sektor usaha penunjang merupakan faktor penentu kemajuan dan bertahannya pelaku usaha dalam kawasan. Sedangkan Dileo ${ }^{6}$ menjelaskan bahwa terjadinya eksternalitas positif, meningkatnya lapangan kerja, meningkatkan produktivitas, pertumbuhan lapangan kerja dan menyebabkan terjadinya keuntungan aglomerasi yang berlanjut merupakan efek yang disebabkan karena adanya keuntungan aglomerasi dalam kawasan.

Keberadaan lokasi usaha dalam kawasan sangat menentukan kelangsungan usaha yang dijalankan, kornita ${ }^{7}$ menjelaskan bahwa sesuai analisis yang dilakukan

4 T.R. et al Manik, 'Kajian Pengembangan Kawasan Agropolitan Seroja Kabupaten Lumajang', Jurnal Tata Kota Dan Daerah, 5.1 (2013), 2013.

5 Y.S Hidayat, 'Analisis Agribisnis Ayam Ras Petelur.', Jurnal Unma. Ac.Id, 2016.

${ }^{6}$ I. Dileo, 'Industrial Aglomeration Facing The Ongoing Economic Crisis: Some Aspects. Cogito', Multidisciplinary Research Journal, 5.1 (2013).

${ }^{7}$ S.E. Kornita, 'Agricultural Development with a New Approach : Case Studies in the Poultry Production Central Area in Mungka Sub-District Lima Puluh Kota Regency.' (Universitas Andalas, 2017).

Analisis Biaya Produksi.... 
berdasarkan teori Weber dinyatakan bahwa lokasi peternakan pada KSP Mungka sudah tepat, aktivitas usaha peternakan ayam ras petelur pada kawasan sentra produksi lebih menguntungkan ditinjau dari aspek biaya, modal dan tenaga kerja.

Selanjutnya apriyeni ${ }^{8}$ menjelaskankan bahwa keunggulan lokasi usaha pada KSP dibandingkan dengan lokasi usaha di luar KSP disebabkan adanya keuntungan aglomerasi yang menyebabkan usaha pada KSP lebih efisien dari sudut biaya produksi, biaya transportasi dengan harga output yang kompetitif. Selanjutnya, Siregar ${ }^{9}$ menekankan pentingnya kebijakan dalam pengaturan tata ruang pada daerah sentra produksi dan pengaturan pola pengusahaan agar tidak terjadi benturan antara usaha besar dan usaha yang berbasis kerakyatan. Sedangkan kemajuan dan keunggulan suatu kawasan menurut Junias ${ }^{10}$ diperlukan sinergisitas yang tinggi antara stakeholder yaitu ; pemerintah pusat, daerah, masyarakat lokal/regional, swasta dan luar negeri untuk percepatan pembangunan daerah sehingga keunggulan daerah yang dimiliki dapat dioptimalkan. Terdapat empat strategi utama pengembangan kawasan yaitu: meningkatkan kredit usaha ${ }^{11}$, pemberian

${ }^{8}$ D. Apriyeni, S. Sjafrizal, and M. Jafrinur, J. Noer, 'The Effect of Agglomeration on Profits and Price Efficiency in Laying Chicken Farming Enterprises in Payakumbuh Production Central Area of Lima Puluh Kota Regency, West Sumatera', Indonesia. Journal of Agricultural, 23.2 (2019).

9 N. Siregar, M., Ilham, 'Upaya Peningkatan Efisiensi Usaha Ternak Ditinjau Dari Aspek Agribisnis Yang Berdaya Saing', Forum Penelitian Agroekonomi, 21.1 (2016); KUSUMA Diwyanto, Atien Priyanti, and Ismeth Inounu, 'Prospek Dan Arah Pengembangan Komoditas Peternakan: Unggas, Sapi Dan KambingDomba', Wartazoa, 15.1 (2005), 11-25.

10 R.S.B. Junias, D.T.S., Elim, M.A. Suharto, 'Kajian Perspektif Pengembangan Wilayah Kabupaten Rote Ndao Sebagai Salah Satu Kawasan Ekonomi Khusus. Jurnal Akutansi, Keuangan Dan Audit', Jurnal Akutansi, Keuangan Dan Audit., 3.1 (2018).

11 Hesi Eka Puteri and Zuwardi Zuwardi, 'Orientasi Budaya Dan Religiusitas Dalam Manajemen Kredit Serta Dampaknya Terhadap Kinerja Sosial Bank

Deltri Apriyeni,, Wati, Meri Rahmania bantuan bibit dan pakan agar dapat meminimalkan biaya produksi, memelihara kontinuitas pemasaran, kestabilan harga bahan baku produksi. ${ }^{12}$ menjelaskan pentingnya penyediaan sarana produksi sesuai dengan keperluan.

Secara teori beberapa ahli menjelaskan pentingnya pemilihan lokasi usaha untuk meminimalkan biaya dan memaksimalkan keuntungan. D.M. Smith dalam ${ }^{13}$, mengintrodusir konsep biaya rata-rata (average cost) dan penerimaan rata-rata (average revenue) yang dikaitkan dengan lokasi produksi. Dapat digambarkan kurva average cost yang berkaitan dengan lokasi dan kurva average revenue. Kurva itu ditentukan oleh selisih average revenue dikurangi average cost tertinggi maka akan terdapat lokasi yang memiliki keuntungan maksimal.

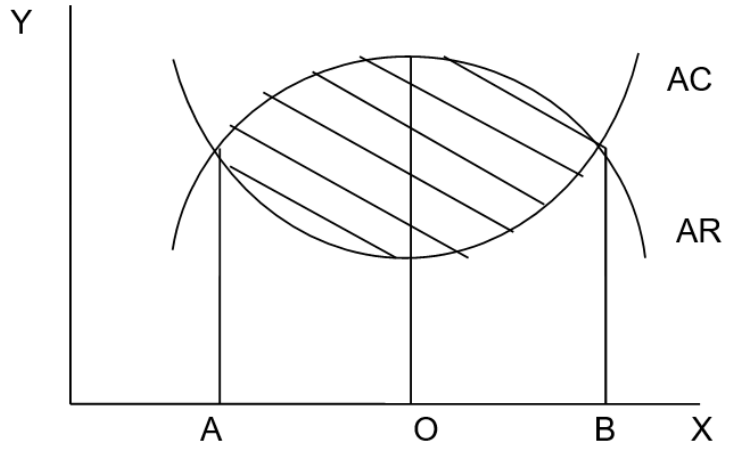

Gambar 1. : Lokasi Untuk Menentukan Keuntungan (Laba) Maksimum, sumber : ${ }^{14}$.

Perkreditan Rakyat', Jurnal Benefita, 1.1 (2019), 196 $<$ https://doi.org/10.22216/jbe.v1i1.3895>.

12 Ikhsan Gunawan and Hamdi Sari Maryoni, 'Dinamika Penetapan Kawasan Ekonomi Khusus Dalam Mempengaruhi Kebijakan Wilayah Desa', Jurnal Sungkai, 5.1 (2017), 69-95; Erna Susanti and Dimas Perdana Oskar, 'Penerapan Bauran Promosi Pada Saluran Distribusi Bagi Produk UMKM Di Kota Padang', EKONOMIKA SYARLAH: Journal of Economic Studies, 3.1 (2019), 56-71; Tessa Yuliani, Liz Izmuddin, and Anne Putri, 'Pengaruh Inovasi Dan Kreativitas Produk Terhadap Ketahanan Ekonomi Masyarakat Pada Industri Kerajinan Kapuk', EKONOMIKA SYARIAH: Journal of Economic Studies, 4.1 (2020), 90110.

13 R. Tarigan, Regional Economy: Theory and Application (Jakarta: Bumi Aksara, 2018).

${ }^{14}$ Tarigan.

Analisis Biaya Produksi... 
Menurut DM. Smith dalam ${ }^{15}$ bahwa: lokasi yang memberikan keuntungan: antara $\mathrm{A}$ dan $\mathrm{B}$ dan yang optimal ada pada titik O. Lebih ke kiri dari titik A atau lebih ke kanan dari titik B maka perusahaan akan menderita kerugian. Selanjutnya Tarigan ${ }^{16}$ menjelaskan bahwa, disamping menentukan lokasi untuk berproduksi yang dekat dengan bahan baku, perlu mempertimbangkan lokasi tempat untuk mendistribusikan hasil output. Dari berbagai studi literatur sebelumnya, perlu dikaji lebih mendalam mengapa peternak yang menempati lokasi usaha pada KSP lebih berkembang usahanya dibandingkan di luar KSP dari segi biaya produksi dan keuntungan usaha. Ditinjau dari jumlah populasi ayam ras petelur yang dipelihara, KSP memilki jumlah populasi yang besar dan terkonsentrasi dalam kawasan. Sementara usaha yang berada di luar KSP, menempati lokasi yang luas antara satu sama lain, terpencar-pencar letak kandangnya atau tidak terkonsentrasi, dengan skala usaha yang relatif kecil bila dibandingkan dengan lokasi peternak di dalam kawasan. Disamping itu, pedagang yang menyediakan saprodi berada lebih banyak di dalam kawasan. Seperti penjual pakan ternak, obat-obatan, vitamin dan suplemen dengan berbagai merek, jasa pembuatan kandang, pabrik pembuatan kertas telur, dll. Bila peternak yang berada di luar kawasan KSP membeli, maka dibebankan ongkos angkut karena jarak yang jauh, sehingga biaya produksi lebih meningkat bila dibandingkan biaya yang dibutuhkan jika berada di dalam kawasan.

Analisis terhadap peran KSP sebagai sentra produksi yang dikenal sebagai kawasan yang mampu menciptakan produksi yang besar, harga bersaing atau kompetitif, skala usaha besar, biaya rendah, keuntungan usaha tinggi sehingga memberikan efisiensi yang tinggi. Menjadi alasan KSP dapat berkembang

15 Tarigan; Sjafrizal and Elfindri, Ekonomi Regional: Teori Dan Aplikasi (Baduose Media, 2008).

16 Tarigan.

Deltri Apriyeni,, Wati, Meri Rahmania pesat, merupakan fokus penelitian yang sangat penting untuk ditelaah lebih dalam dan perlu dibuktikan secara empiris. Jika dilihat secara kasat mata tidak ada perbedaan antara usaha yang berada dalam kawasan maupun usaha yang berada di luar kawasan. Namun demikian perlu diuji secara ilmiah bahwa kedua lokasi peternakan ini memang berbeda dari segi biaya produksi dan keuntungan usaha yang diperoleh peternak.

Hipotesis dalam penelitian ini adalah : Ho : Diduga tidak terdapat perbedaan biaya produksi dan keuntungan usaha antara KSP dan luar KSP. Ha : Diduga terdapat terdapat perbedaan biaya produksi dan keuntungan usaha antar KSP dan luar KSP.

\section{Metodologi}

KSP Payakumbuh berada pada lokasi Kecamatan Payakumbuh, Kabupaten Lima Puluh Kota Propinsi Sumatera Barat, Indonesia. Berdasarkan letak geografis .00"N and 100037'58.80'"E. ${ }^{17}$.

Populasi penelitian ini adalah peternak ayam petelur di PCA Payakumbuh dan di luar PCA. Ke 67 peternak di Kecamatan Payakumbuh itu semuanya dilibatkan. Demikian pula, 67 peternak di luar PCA digunakan. Tiga kecamatan di luar PCA adalah Kecamatan Luhak, Kabupaten Lareh Sago Halaban dan Kabupaten Situjuah Limo Nagari. Kuisioner dan wawancara mendalam selama digunakan dalam pengumpulan data primer sedangkan data sekunder diperoleh dari instansi terkait, yang memberikan informasi tentang karakteristik wilayah daerah tersebut.

Table 1: Jumlah peternak dan produksi telur di Kabupaten Lima Puluh Kota 2016

17 Central_Bureau_of_Statistics, 'Statistic of Lima Puluh Kota Regency 2016', 2016.

Analisis Biaya Produksi.... 
EKONOMIKA SYARIAH:

Journal of Economic Studies
e-ISSN: 2614-8110

p-ISSN: 2614-7890

\begin{tabular}{lcrr}
\hline Districts & $\begin{array}{c}\text { Number of } \\
\text { breeders }\end{array}$ & $\begin{array}{c}\text { Population } \\
\text { of laying } \\
\text { chicken } \\
\text { eggs }\end{array}$ & $\begin{array}{c}\text { Number of } \\
\text { egg } \\
\text { production } \\
\text { per year }\end{array}$ \\
\hline Payakumbuh PCA & 67 & 1.503 .255 & $11.590 .096,05$ \\
Akabiluru & 13 & 178.580 & $1.376 .851,80$ \\
Luak & 17 & 349.600 & $2.695 .416,00$ \\
Lareh Sago Halaban & 43 & 536.525 & $4.136 .607,75$ \\
Situjuah Limo Nagari & 15 & 271.440 & $2.092 .802,40$ \\
Harau & 48 & 560.500 & 4.321 .455 .00 \\
Guguk PCA & 22 & 677.000 & $5.219 .670,00$ \\
Mungka PCA & 17 & 772.515 & $5.956 .090,65$ \\
Suliki & 7 & 128.775 & $992.701,05$ \\
Bukit Barisan & 1 & 455 & $3.508,05$ \\
& & & \\
\hline Total & 250 & 4.978 .625 & $38.385 .198,75$ \\
\hline
\end{tabular}

Sumber : West Sumatera Livestock and Animal Health Department, 2016.

Biaya produksi diukur berdasarkan biaya yang dikeluarkan oleh peternak meliputi : pembelian bibit, biaya pakan, obat-obatan dan vaksin, upah tenaga kerja. Keuntungan usaha dihitung melalui total penerimaan hasil output yang diperoleh peternak dikurang dengan total biaya input produksi. Biaya produksi dan keuntungan usaha yang diperoleh dihitung dalam jangka waktu satu bulan.

\section{Hasil dan Diskusi}

\section{Karakteristik peternak ayam ras petelur}

Berikut ini hasil data penelitian berupa data karakteristik peternak pada KSP Payakumbuh dan dan lokasi di luar KSP.

Table 2 : Karakteristik Sosial Ekonomi Peternak Ayam Ras Petelur Pada KSP dan di luar KSP
A. Characteristics
B. KSP
C. Outsite Ksp

\begin{tabular}{|c|c|c|c|c|c|c|c|c|}
\hline & $D$. & $\begin{array}{l}\text { Number } \\
(n=67)\end{array}$ & $E$ & $\begin{array}{c}\text { Percentage } \\
(n=67)\end{array}$ & & Number $(n=67)$ & G. & $\begin{array}{c}\text { Percentage } \\
(n=67)\end{array}$ \\
\hline Age & $H$. & & $I$. & & $J$. & & $K$ & \\
\hline$<30$ & & 6 & & 8.96 & & 8 & & 11.94 \\
\hline $30-39$ & & 25 & & 37.32 & & 28 & & 41.79 \\
\hline $40-49$ & & 18 & & 26.86 & & 23 & & 34.32 \\
\hline & & 18 & & 26.86 & & 8 & & 11.95 \\
\hline
\end{tabular}

\begin{tabular}{|c|c|c|c|c|}
\hline Education level & $L$. & M. & $N$. & $O$ \\
\hline $\mathrm{SD}$ & 3 & 11.48 & 3 & 4.48 \\
\hline SLTP & 13 & 19.40 & 18 & 26.86 \\
\hline SLTA & 39 & 58.20 & 34 & 50.75 \\
\hline Perguruan Tinggi & 12 & 17.92 & 12 & 17.91 \\
\hline Gender & $P$. & $Q$ & $R$. & $S$. \\
\hline Male & 54 & 80.60 & 53 & 79.10 \\
\hline Female & 13 & 19.40 & 14 & 20.90 \\
\hline Experience & $T$. & $U$ & $V$ & $W$ \\
\hline$<5$ years & 9 & 13.43 & 13 & 19.40 \\
\hline $5-10$ years & 10 & 14.92 & 24 & 35.82 \\
\hline 10 years & 48 & 71.65 & 30 & 44.78 \\
\hline
\end{tabular}

\section{Chicken Population}

$X$.

$Y$.

$Z$.

$A A$. 


\begin{tabular}{ccccc}
\hline$\leq 4999$ & 6 & 8.95 & 4 & 5.96 \\
\hline $5000-14.999$ & 18 & 26.86 & 39 & 58.20 \\
\hline $15.000-24.999$ & 14 & 20.89 & 11 & 16.41 \\
\hline $25.000-34.999$ & 8 & 11.94 & 3 & 4.47 \\
\hline $35.000-44.999$ & 5 & 7.46 & 4 & 5.96 \\
\hline $45.000-54.999$ & 10 & 14.93 & 1 & 1.50 \\
\hline $55.000-64.999$ & - & - & 1 & 1.50 \\
\hline $65.000-74.999$ & 3 & 4.47 & 1 & 1.50 \\
\hline $75.000-84.999$ & 1 & 1.50 & 1 & 1.50 \\
\hline $85.000-94.999$ & - & - & - & - \\
\hline $95.000-104.999$ & 1 & 1.50 & 1 & - \\
\hline $135.000-144.999$ & 1 & 1.50 & - & 1.50 \\
\hline$>145.000$ & - & - & 1 & \\
\hline
\end{tabular}

Sumber: Hasil penelian 2017

Berdasarkan data karakteristik peternak (umur, tingkat pendidikan, jenis kelamin, pengalaman) pada lokasi KSP dan di luar KSP, tidak terdapat perbedaan yang terlalu jauh. Pada populasi ternak ayam ras terdapat skala usaha yang lebih besar antara peternak pada KSP dibandingkan di luar KSP. Pada skala 45.000 hingga 150 ribu ekor masih di dominasi oleh peternak yang berlokasi pada KSP. Sedangkan pada lokasi usaha di luar KSP jumlah populasi ayam yang dipelihara oleh peternak sebagian besar berskala di bawah 50.000 ekor. Dari data ini dapat diambil kesimpulan bahwa usaha peternakan ayam ras petelur yang menempati lokasi pada KSP lebih berkembang dengan pesat dibandingkan dengan kawasan di luar KSP. Hal yang sama juga dijelaskan oleh beberapa peneliti ${ }^{18}$ dengan lokasi penelitian pada KSP Mungka dan KSP Payakumbuh, bahwa usaha peternakan yang berada pada lokasi KSP lebih maju dan berkembang dibandingkan dengan peternak yang berusaha di luar KSP.

\section{Perbedaan Biaya Produksi}

Uji beda atau uji signifikansi atau uji t test bertujuan untuk membuktikan bahwa usaha peternakan ayam ras petelur yang berada pada dua lokasi yaitu pada KSP dan di luar Noer.

18 Kornita; Apriyeni, Sjafrizal, and Jafrinur, J.
KSP berbeda berdasarkan variabel yang diukur. Variabel yang diukur dalam penelitian ini yaitu; nilai biaya produksi rata-rata dan nilai keuntungan usaha rata-rata pada kedua lokasi usaha. Data yang berasal dari kedua lokasi usaha tidak saling berhubungan satu sama lain, maka digunakan uji beda yang disebut dengan independent sample $t$ test atau Mann-Whitney U-Test.

Berikut ini adalah tabel hasil uji beda biaya produksi antara usaha peternakan ayam ras petelur yang berada pada KSP dan di luar KSP.

Table 3. Hasil Uji Beda Biaya Produksi Ratarata Pada KSP dan di luar KSP

\begin{tabular}{lccccc}
\hline & Group & $\mathrm{N}$ & Mean & Std. Deviation & $\begin{array}{c}\text { Std. Error } \\
\text { Mean }\end{array}$ \\
\hline $\begin{array}{l}\text { Cost } \\
\text { Production }\end{array}$ & 0 & 67 & 979.19 & 58.277 & 7.120 \\
\hline & 1 & 67 & 893.45 & 59.851 & 7.312 \\
\hline
\end{tabular}

Sumber: Hasil penelitian 2017

$0=$ Luar KSP

$1=$ Dalam KSP

Dari Tabel 3 terlihat bahwa rata-rata biaya produksi usaha peternakan ayam ras petelur pada KSP lebih rendah dari pada di luar KSP. Artinya efisiensi dalam berproduksi lebih tinggi pada usaha yang berada pada lokasi KSP dibandingkan dengan usaha yang berada di luar KSP. Berproduksi dalam skala yang lebih besar dan berlokasi terpusat dalam kawasan dapat 
meringankan biaya yang dikeluarkan oleh peternak disamping faktor pendukung usaha yang berada dalam KSP. Berbagai usaha pendukung dan usaha terkait yang menyokong usaha peternakan memilih lokasi usaha pada KSP, seperti pedagang sarana produksi (pakan, obat-obatan, vaksin, jasa pembuatan kandang, jasa transportasi) yang diperlukan peternak. Sehingga peternak yang berlokasi pada KSP lebih mudah memperoleh sarana produksi dan biaya yang lebih rendah dibandingkan dengan peternak di luar lokasi KSP. Sejalan dengan pernyataan ${ }^{19}$ bahwa besarnya biaya dalam berproduksi merupakan kendala utama yang dihadapi peternak. Biaya produksi yang tinggi terutama biaya pakan, vaksin dan obatobatan, persaingan dan fluktuasi harga di pasaran dapat menghambat efisiensi dalam berproduksi. Selain itu, keberadaan kawasan ini turut meringankan biaya transportasi ${ }^{20}$. Hal tersebut didukung oleh: ${ }^{21}$ bahwa biaya transportasi yang tinggi, skala usaha yang kecil karena terkendala modal yang dimiliki merupakan kendala yang dihadapi dalam usaha.

${ }^{19}$ Kshash, B., dan Oya (2019)

${ }^{20}$ Kornita.

${ }^{21}$ Enibe, D.O., Eze, A.O., Ugwuoke (2018)

Deltri Apriyeni,, Wati, Meri Rahmania 
Tabel 4. Hasil Uji Beda Biaya Produksi Pada KSP dan di luar KSP

\begin{tabular}{|c|c|c|c|c|c|c|c|c|c|c|}
\hline \multirow{5}{*}{$\begin{array}{c}\text { Biaya } \\
\text { Produksi }\end{array}$} & \multirow{5}{*}{$\begin{array}{c}\text { Equal } \\
\text { variances } \\
\text { assumed } \\
\text { Equal } \\
\text { variances } \\
\text { not } \\
\text { assumed }\end{array}$} & \multicolumn{2}{|c|}{$\begin{array}{c}\text { Levene's Test } \\
\text { for Equality of } \\
\text { Variances }\end{array}$} & \multicolumn{7}{|c|}{ t-test for Equality of Means } \\
\hline & & & & & & & & & \multicolumn{2}{|c|}{$\begin{array}{l}95 \% \text { Confidence } \\
\text { Interval of the } \\
\text { Difference }\end{array}$} \\
\hline & & $F$ & Sig. & $\mathrm{t}$ & $\mathrm{df}$ & $\begin{array}{c}(2- \\
\text { tailed) }\end{array}$ & $\begin{array}{c}\text { Mean } \\
\text { Difference }\end{array}$ & $\begin{array}{l}\text { Std. Error } \\
\text { Difference }\end{array}$ & Lower & Upper \\
\hline & & .053 & .818 & 8.402 & 132 & .000 & 85.746 & 10.206 & 65.559 & 105.934 \\
\hline & & & & 8.402 & 131.906 & .000 & 85.746 & 10.206 & 65.558 & 105.934 \\
\hline
\end{tabular}

Sumber : Hasil penelitian, 2017

Keterangan

$0=$ Luar KSP

$1=$ Dalam KSP

Berdasarkan uji beda yang dilakukan terbukti bahwa diperoleh perbedaan yang signifikan dalam biaya produksi yang dikeluarkan oleh peternak pada kedua lokasi. Dengan nilai signifikansi (Sig, 2-tailed) 0,000 $<0,05$, berarti hipotesa awal (Ho) ditolak dan hipotesa akhir (Ha) diterima. Peternak pada KSP memiliki biaya produksi yang lebih rendah dibandingkan dengan peternak yang berada di luar lokasi KSP. Rendahnya biaya produksi pada KSP menunjukkan bahwa usaha ini lebih efisien, harga output yang kompetitif membuat usaha ini terus berkembang ditunjukkan dengan data populasi ayam ras petelur yang lebih besar populasinya.

\section{Perbedaan Biaya Keuntungan}

Keuntungan usaha yang menjanjikan dalam usaha yang dilakoni merupakan faktor kuat yang dapat memotivasi peternak dalam menjalankan usaha. Ketekunan, kerajinan serta keyakinan harus dimiliki peternak karena usaha ini menuntut hal yang demikian agar dapat survive ditengah persaingan usaha. Peternak harus memiliki terobosan yang inovatif bagaimana cara yang tepat untuk menekan biaya produksi dan memaksimalkan keuntungan yang akan diperoleh. Hal ini dapat dilakukan dengan menemukan formula ransum yang tepat nilai gizinya dengan biaya yang rendah. Siapa yang mampu melakukan efisiensi yang tinggi tentu akan memenangkan persaingan dan dapat terus mengembangkan usaha yang ada semakin maju dan berkembang.

Berikut adalah tabel hasil uji beda yang dilakukan antara peternak yang menempati dua lokasi usaha, yang diukur berdasarkan hasil uji keuntungan usaha yang diperoleh peternak.

Table 5. Hasil Uji Beda Keuntungan Ratarata Usaha Pada KSP dan di luar KSP

\begin{tabular}{lccccc}
\hline & & Group & $\mathrm{N}$ & \multicolumn{4}{c}{ Mean } & Std. Deviation & Std. Error Mean \\
\hline $\begin{array}{l}\text { Business } \\
\text { Benefits }\end{array}$ & 0 & 67 & 134.27 & 43.322 & 5.293 \\
\hline & 1 & 67 & 150.18 & 42.679 & 5.214 \\
\hline
\end{tabular}

Sumber: Hasil penelitian 2017

Dari hasil uji beda terlihat bahwa usaha yang berada pada KSP lebih menguntungkan dibandingkan dengan usaha yang berada di luar KSP. Besarnya keuntungan yang diperoleh disebabkan karena biaya dalam berproduksi pada lokasi usaha yang berada pada KSP lebih rendah dibandingkan dengan usaha yang berada di luar KSP. Meskipun harga pokok penjualan pada lokasi di luar KSP lebih tinggi dibandingkan pada KSP tidak menyebabkan keuntungan yang diterima peternak yang berada di luar KSP lebih besar dibandingkan 
Table 6. Hasil Uji Beda Keuntungan Usaha Pada KSP dan di luar KSP

\begin{tabular}{|c|c|c|c|c|c|c|c|c|c|c|}
\hline & & $\begin{array}{l}\text { Lev } \\
\text { Tes } \\
\text { Equa } \\
\text { Vari }\end{array}$ & $\begin{array}{l}\text { ie's } \\
\text { for } \\
\text { y of } \\
\text { ces }\end{array}$ & & & $\mathrm{t}$-test $\mathrm{fo}$ & Equality & of Means & & \\
\hline & & & & & & & & & $\begin{array}{r}95 \% \mathrm{Co} \\
\text { Interva } \\
\text { Diffe }\end{array}$ & $\begin{array}{l}\text { idence } \\
\text { ff the } \\
\text { nce }\end{array}$ \\
\hline & & $\mathrm{F}$ & Sir & t & df & Sig. (2- & $\begin{array}{l}\text { Mean } \\
\text { Differ }\end{array}$ & $\begin{array}{c}\text { Std. } \\
\text { Error } \\
\text { Differen }\end{array}$ & Lower & Unner \\
\hline $\begin{array}{l}\text { Business } \\
\text { Benefits }\end{array}$ & $\begin{array}{c}\text { Equal } \\
\text { variances }\end{array}$ & .067 & .796 & -2.142 & 132 & .034 & $15.910^{-}$ & 7.430 & -30.607 & -1.214 \\
\hline 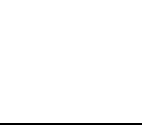 & $\begin{array}{c}\text { Equal } \\
\text { variances not } \\
\text { assumed }\end{array}$ & & & -2.142 & 131.971 & .034 & $15.910^{-}$ & 7.430 & -30.607 & -1.214 \\
\hline amber: $\mathrm{Has}$ & enelitian 2017 & & & & & & & & & \\
\hline $\begin{array}{l}\text { Teterangan } \\
=\text { Luar } \\
=\text { Dalan }\end{array}$ & & & & & & & & & & \\
\hline
\end{tabular}

Berdasarkan uji signifikansi atau uji beda dapat diambil kesimpulan bahwa keuntungan usaha yang diperoleh oleh peternak ayam ras petelur lebih besar pada usaha yang berada pada lokasi KSP dibandingkan dengan lokasi di luar KSP. Dengan nilai signifikansi (Sig, 2tailed) $0,034<0,05$, berarti hipotesa awal (Ho) ditolak dan hipotesa akhir ( $\mathrm{Ha})$ diterima. Hal ini disebabkan karena usaha yang berada pada lokasi KSP lebih efisien dalam berproduksi dan mampu menciptakan harga yang berdaya saing dengan skala usaha yang lebih besar di bandingkan dengan usaha yang berada di luar lokasi KSP. Disamping itu akses pasar yang lebih baik, kemudahan dalam berproduksi karena tersedianya sarana pendukung dalam produksi pada kawasan turut menentukan keuntungan usaha yang diperoleh oleh peternak. Hal ini dijelaskan oleh ${ }^{22}$ bahwa, keuntungan usaha yang diperoleh ditentukan oleh akses pasar, kemudahan dalam berproduksi, akses dalam pemberian kredit usaha. Perhatian pemerintah turut menentukan kemajuan

$$
22 \text { Shuaibu (2018) }
$$

Deltri Apriyeni, Wati, Meri Rahmania usaha dengan menyediakan infrastruktur yang layak ${ }^{23}$. Drastiani ${ }^{24}$ juga sependapat dengan ${ }^{25}$ bahwa infrastruktur penunjang perlu untuk iklim berusaha. Kemudian Fastabiqul ${ }^{26}$ menekankan bahwa kawasan sentra bertujuan meningkatkan efisiensi dan menurunkan biaya yang bermuara pada pertumbuhan ekonomi. ${ }^{27}$, memberikan saran

${ }^{23}$ M.M. et all Bello, 'The Economic Effect of Insurgency on Smoked Fish Sellers in MaiduguriMetropolis of Borno State Nigeria.', Journal of Agricultural Extension, 21.3 (2018); Muinat Moninuola Bello and others, 'The Economic Effect of Insurgency on Smoked Fish Sellers in Maiduguri Metropolis of Borno State Nigeria', Journal of Agricultural Extension, 21.3 (2017), 37-45; Ryohei Nakamura and Catherine J Morrison Paul, 'Measuring Agglomeration', in Handbook of Regional Growth and Development Theories (Edward Elgar Publishing, 2019).

${ }^{24}$ Drastiani (2014)

${ }^{25}$ Bello (2018)

${ }^{26}$ K. Fastabiqul, 'Perkembangan Aspek Sosial, Ekonomi Dan Fisik Pada Kawasan Sentra Produksi (KSP) Padi Dan Dampaknya Pada Usaha Tani Padi (Studi Kasus Kecamatan Ampek Angkek Dan Kecamatan Kamang Magek, Kabupaten Agam.', 2018; Linda Umasugi, 'Pemetaan Kawasan Sentra Produksi Bagi UMKM Di Kota Ternate', Agrikan: Jurnal Agribisnis Perikanan, 11.1 (2018), 43-48.

${ }^{27}$ Lawal (2017)

Analisis Biaya Produksi... 
untuk menekan biaya produksi maka harga pakan harus dapat ditekan dengan membangun pabrik pakan. Sesuai dengan saran Lawal tersebut, hal ini memang mutlak untuk jadi bahan pertimbangan bagi pemerintah selaku pengambil kebijakan untuk memajukan KSP. Sependapat dengan Lawal, Hikmah ${ }^{28}$ menguatkan bahwa pentingnya kebijakan yang berpihak kepada pelaku ekonomi lokal khususnya dalam pemasaran guna memajukan kawasan sentra produksi.

\section{Kesimpulan dan Rekomendasi}

Berdasarkan hasil uji beda, usaha peternakan yang menempati kawasan sentra produksi dan diluar kawasan sentra produksi terbukti berbeda dari segi biaya produksi dan keuntungan usaha yang diperoleh. Usaha yang pada kawasan sentra produksi lebih rendah dalam biaya produksi dan lebih tinggi tingkat keuntungan yang diperoleh oleh peternak dibandingkan dengan lokasi usaha di luar kawasan.

Diharapkan pemerintah khususnya institusi yang terkait, memperhatikan kondisi kawasan beserta unsur penunjang dan infrastruktur yang terdapat pada kawasan. Menjadi kawasan yang memadai sebagai wadah yang dapat diandalkan oleh peternak sebagai penunjang usaha. Agar komponen biaya produksi dapat ditekan lagi dan keuntungan yang diperoleh semakin bertambah, harga jual output produksi lebih bersaing di pasaran. Menjadikan KSP sebagai kawasan yang tepat untuk dipilih sebagai lokasi usaha. Mengingat kondisi KSP yang ada sekarang belum memenuhi syarat sebagaimana kawasan yang layak secara bisnis namun keberadaan KSP sudah memberikan kontribusi berarti bagi peternak yang menempati lokasi.

${ }^{28}$ Hikmah (2017)

Deltri Apriyeni, Wati, Meri Rahmania
Pentingnya keterlibatan pemerintah selaku pengambil kebijakan mengingat usaha peternakan ini merupakan lokomotif bergeraknya ekonomi. Memberikan efek multiplier bagi usaha lainnya. Dilakoni oleh masyarakat lokal dimana banyak menyerap tenaga kerja setempat. Secara ekonomi syariah, perlu menciptakan keadilan dalam berusaha terutama dalam perolehan keuntungan usaha baik yang berada dalam kawasan maupun yang di luar kawasan. .

\section{Daftar Pustaka}

Ali, Misbahul, 'Prinsip Dasar Produksi Dalam Ekonomi Islam', LISAN AL-HAL: Jurnal Pengembangan Pemikiran Dan Kebudayaan, 7.1 (2013), 19-34

Amshari, M, 'Analisis Biaya Dan Efisiensi Produksi Dalam Ekonomi Islam', Jurnal Balanca, 1.1 (2019)

Apriyeni, D., S. Sjafrizal, and M. Jafrinur, J. Noer, 'The Effect of Agglomeration on Profits and Price Efficiency in Laying Chicken Farming Enterprises in Payakumbuh Production Central Area of Lima Puluh Kota Regency, West Sumatera', Indonesia. Journal of Agricultural, 23.2 (2019)

Bello, M.M. et all, 'The Economic Effect of Insurgency on Smoked Fish Sellers in MaiduguriMetropolis of Borno State Nigeria.', Journal of Agricultural Extension, 21.3 (2018)

Bello, Muinat Moninuola, Hamidu Sani, Ahmadu Bukar, and Maryam Mohd Rabiu, 'The Economic Effect of Insurgency on Smoked Fish Sellers in Maiduguri Metropolis of Borno State Nigeria', Journal of Agricultural Extension, 21.3 (2017), 37-45

Central_Bureau_of_Statistics, 'Statistic of Lima Puluh Kota Regency 2016’, 2016

Dileo, I., 'Industrial Aglomeration Facing The Ongoing Economic Crisis : Some Aspects. Cogito', Multidisciplinary Research Journal, 5.1 (2013)

Analisis Biaya Produksi.... 
Diwyanto, KUSUMA, Atien Priyanti, and Ismeth Inounu, 'Prospek Dan Arah Pengembangan Komoditas Peternakan: Unggas, Sapi Dan Kambing-Domba', Wartaroa, 15.1 (2005), 11-25

Drastiani, R., 'Pengembangan Kawasan Tangga Buntung Sebagai Creative Cluster Industry Di Kawasan Wisata Tepian Ilir Sungai Musi Palembang. Etd.' (repository. ugm.ac.id., 2014)

Enibe, D.O., Eze, A.O., Ugwuoke, B.C., 'Economics of Pineapple Marketing in Anambra State, Nigeria.', Journal of Agricultural Extension, 22.2 (2018)

Faizah, Fita Nurotul, 'Teori Produksi Dalam Studi Ekonomi Islam Modern: Analisis Komparatif Pemikiran Muhammad Baqir Al-Sadr Dan Muhammad Abdul Mannan' (UIN Walisongo, 2016)

Fastabiqul, K., 'Perkembangan Aspek Sosial, Ekonomi Dan Fisik Pada Kawasan Sentra Produksi (KSP) Padi Dan Dampaknya Pada Usaha Tani Padi (Studi Kasus Kecamatan Ampek Angkek Dan Kecamatan Kamang Magek, Kabupaten Agam.', 2018

Gunawan, Ikhsan, and Hamdi Sari Maryoni, 'Dinamika Penetapan Kawasan Ekonomi Khusus Dalam Mempengaruhi Kebijakan Wilayah Desa', Jurnal Sungkai, 5.1 (2017), 6995

Hidayat, Y.S, 'Analisis Agribisnis Ayam Ras Petelur.', Jurnal Unma. Ac.Id, 2016

Hikmah., Purnomo, A. H., 'Saluran, Margin Dan Efisiensi Pemasaran Rumput Laut Di Sentra Kawasan Minapolitan Kabupaten Sumbawa.', Buletin Ilmiah 'Marina' Sosial Ekonomi Kelautan Dan Perikanan., 3.2 (2017), 61-69

Junias, D.T.S., Elim, M.A. Suharto, R.S.B., 'Kajian Perspektif Pengembangan Wilayah Kabupaten Rote Ndao Sebagai Salah Satu Kawasan Ekonomi Khusus. Jurnal Akutansi, Keuangan Dan Audit', Jurnal Akutansi, Keuangan
Dan Audit., 3.1 (2018)

Kornita, S.E., 'Agricultural Development with a New Approach : Case Studies in the Poultry Production Central Area in Mungka Sub-District Lima Puluh Kota Regency.' (Universitas Andalas, 2017)

Kshash, B., Oya, H., 'Constraints Facing Poultry Producers in Iraq.', Journal of Agricultural Extension, 23.2 (2019)

Lawal, A.M., Amolegbe, K.B., Abdulsalam, A.O., 'Economics of Quail Production in Ilorin, Kwara State in Nigeria.', Journal of Agricultural Extension., 21.2 (2017)

Manik, T.R. et al, 'Kajian Pengembangan Kawasan Agropolitan Seroja Kabupaten Lumajang', Jurnal Tata Kota Dan Daerah, 5.1 (2013), 2013

Nakamura, Ryohei, and Catherine J Morrison Paul, 'Measuring Agglomeration', in Handbook of Regional Growth and Development Theories (Edward Elgar Publishing, 2019)

Puteri, Hesi Eka, and Zuwardi Zuwardi, 'Orientasi Budaya Dan Religiusitas Dalam Manajemen Kredit Serta Dampaknya Terhadap Kinerja Sosial Bank Perkreditan Rakyat', Jurnal Benefita, $1.1 \quad$ (2019), 196 <https://doi.org/10.22216/jbe.v1i1.3 $895>$

Shuaibu, H. Et all., 'Socio-Economic Factors and Profitability of Groundnut Processing by Women in Kano State, Nigeria.', Journal of Agricultural Extension, 22.2 (2018)

Siregar, M., Ilham, N., 'Upaya Peningkatan Efisiensi Usaha Ternak Ditinjau Dari Aspek Agribisnis Yang Berdaya Saing', Forum Penelitian Agroekonomi, 21.1 (2016)

Sjafrizal, and Elfindri, Ekonomi Regional: Teori Dan Aplikasi (Baduose Media, 2008)

Sjafrizal, S, Regional Economic Analysis and Its Application (Jakarta: PT. Rajawali Pers, 2018)

Analisis Biaya Produksi.... 
Susanti, Erna, and Dimas Perdana Oskar, 'Penerapan Bauran Promosi Pada Saluran Distribusi Bagi Produk UMKM Di Kota Padang', EKONOMIKA SYARLAH: Journal of Economic Studies, 3.1 (2019), 56-71

Tarigan, R., Regional Economy: Theory and Application (Jakarta: Bumi Aksara, 2018)

Umasugi, Linda, 'Pemetaan Kawasan Sentra Produksi Bagi UMKM Di Kota Ternate, Agrikan: Jurnal Agribisnis Perikanan, 11.1 (2018), 43-48

Wahyuni, S., 'Teori Konsumsi Dan Produksi Dalam Perspektif Ekonomi Islam', Jurnal Akuntabel, 10.1 (2013)

Yuliani, Tessa, Liz Izmuddin, and Anne Putri, 'Pengaruh Inovasi Dan Kreativitas Produk Terhadap Ketahanan Ekonomi Masyarakat Pada Industri Kerajinan Kapuk', EKONOMIKA SYARLAH: Journal of Economic Studies, 4.1 (2020), 90-110 